\title{
Micro-scale computer modelling of the relationship between metallurgical microstructure and localized corrosion effects
}

\author{
S. G. R. Brown \& N. C. Barnard \\ Materials Research Centre, School of Engineering, \\ Swansea University, Singleton Park, Swansea, UK
}

\begin{abstract}
An attempt is made to model the corrosion effects experienced by zinc and zinc-aluminium coating alloys in contact with conductive, chloride containing aqueous electrolytes. 3D predictions of localized corrosion of zinc alloy coatings are made using a control-volume finite difference approach, where an irregular structured mesh is employed. The model deals with the movement of multiple evolving conserved concentration fields. Perturbations in concentration are used to determine the conditions at an exposed surface, in addition to influencing any processes operating. The effect of coupled-materials and electrolyte present on the progression of localized corrosion processes is calculated using established relationships and experimentally derived data.

Quantitative predictions of the corrosion performance at the exposed surface and cut-edge to electrolyte (used in the accelerated corrosion testing of these coating alloys) are made. Comparison is made to the predicted form of the current density fields around corroding surfaces and those observed experimentally. In addition, absolute metal losses calculated across exposed areas of the simulated alloys are compared with those estimated during experimental investigations.
\end{abstract}

Keywords: zinc alloy coatings, localized dissolution, finite difference method.

\section{Introduction}

As the cost of corrosion processes accounts for $c a$ 5\% GDP of the developed nations, it is no wonder that a great deal of interest exists in protecting the world's infrastructure and durable goods. The use of steel in many applications 
means that the protection of these goods/structures against the deleterious effects of corrosion processes is of considerable concern. For in excess of a century, zinc has played a major role in the efforts of corrosion scientists and engineers to protect steel against corrosive attack. The use of zinc and its alloys in this respect derives from its ability to provide both barrier and sacrificial protection to the electrically-connected steel.

Zinc may be used in a completely sacrificial capacity, although it is more commonplace to coat a substrate (predominantly strip steel) either via electroplating or more commonly via hot-dip methods. The hot-dipping process consists of the continuous-feeding of a steel strip through a molten zinc alloy. The composition of this alloy, the processing conditions [1] and the complex bath chemistry taking-place ultimately lead to the formation of widely varying microstructures observed for the different $\mathrm{Zn}$ alloys produced. For example, a common addition the hot-dip bath is Al that can be added at low levels during the production of ordinary galvanized steels and an increased level (eutectic composition) of $\sim 4.5 \mathrm{wt} . \% \mathrm{Al}$ for a Galfan-type alloy. An increase to $55 \mathrm{wt} . \% \mathrm{Al}$ produces a Galvalume $\mathrm{ZnAl}$ alloy, all of which exhibit different microstructures owing to the processes taking place prior to, during and post hot-dipping, e.g. reaction-diffusion at the solid-liquid interface. Other factors such as texture [2] play a role in the corrosion performance, although these are not considered here. Further additions to the bath modify the microstructure further, leading to a wide variety of $\mathrm{Zn}$ alloy steel coatings with characteristic corrosion properties.

There is significant interest in the corrosion performance $\mathrm{Zn}-\mathrm{Al}$ alloy coated steel in the service environment. To this end many attempts to assess the degradation experienced in aqueous and atmospheric [3] environments over different timescales are made. Scanning electrochemical techniques [4] and impedance spectroscopy [5] are often employed in order to predict the degradation of a $\mathrm{Zn}$ alloy coating in an aggressive chloride-containing electrolyte in order to elucidate the corrosion behaviour in the service environment. The focus of this paper is an attempt to model the corrosion behaviour of $\mathrm{Zn} / \mathrm{ZnAl}$ coatings in $5 \% \mathrm{NaCl}$ solutions: typically used in accelerated testing using the scanning vibrating electrode technique (SVET). This permits validation of the computer model using experimentally determined data.

This paper outlines an attempt to model the localized dissolution of zinc from zinc and zinc-aluminium alloy coatings used in the protection of steel. Developed from a metallurgical standpoint, the aim is to quantitatively predict the ionic evolution of multiple species from the coating layers as well as the temporal changes in electrical potential in the electrolyte brought about by metallic dissolution. In order to capture the dominant processes taking place during the dissolution from the steel coatings and the effects of the microstructures present, the model has been developed at the micro-mesoscale. A $3 \mathrm{D}$ irregular orthogonal grid is used to represent the solid and liquid phases present. Finite difference calculations of potential and concentration are performed on this structured mesh, thus predicting the localized dissolution from the coating layers of interest using established electrochemical relationships. 


\section{Dissolution modelling in aqueous $\mathrm{NaCl}$}

The algorithm presented is an extension of a first order model developed previously, whereby the evolving ionic concentration was approximated by the changes in effective free proton concentration [6,7]. All simulations are performed at $\mathrm{pH}$ neutral conditions and are isothermal at $298 \mathrm{~K}$.

\subsection{Computational domain}

As previously stated, the model is designed to operate at the micro-mesoscale. A 3D irregular structured orthogonal mesh is used to represent steel and coatings in contact with an electrolyte using a typical area of exposure of about $1 \mathrm{~mm}^{2}$. A usual setup for the grid would be the allocation of half of the cells present as solid. These cells are labelled as being zinc, steel or zinc-aluminium sites. A solid site contains information about the composition, volume fraction that is solid $(f)$, and electrical potential $(\phi)$. Each liquid site possesses an electrical potential $(\phi)$, volume fraction of corrosion product $(p)$, current density vector $\left(i_{x} i_{y} i_{z}\right)$ and concentrations $(c)$ of the conserved fields; $\left[\mathrm{M}^{\mathrm{n}+}\right],\left[\mathrm{O}_{2}\right],\left[\mathrm{OH}^{-}\right]$and $\left[\mathrm{H}^{+}\right]$. Variable grid spacings $(\Delta x, \Delta y, \Delta z)$ for each cell in the mesh are also stored.

The representation of the microstructure is entirely synthetic and a near eutectic composition of $\mathrm{Zn}-4.5 \mathrm{wt} . \% \mathrm{Al}$ is used, since the intermetallic formation in this hot-dip coating is limited. The microstructure of this Galfantype coating is one of primary zinc crystals within a $\mathrm{ZnAl}$ eutectic that contains approximately $5 \mathrm{wt} . \% \mathrm{Al}$.

\subsection{Metallic dissolution}

The basis of the model is the removal of metallic constituents from the coating layers via equation 1 . This then brings about concentration perturbations, altering the surface/bulk electrolyte conditions and thereby the cathodic protection offered to the steel.

$$
\begin{gathered}
\mathrm{M}_{(\mathrm{s})} \rightarrow \mathrm{M}_{(\mathrm{aq})}^{\mathrm{n}+}+\mathrm{ne}^{-} \\
\mathrm{O}_{2(\mathrm{~g})}+2 \mathrm{H}_{2} \mathrm{O}_{(\mathrm{l})}+4 \mathrm{e}^{-} \rightarrow 4 \mathrm{OH}_{(\mathrm{aq})}^{-}
\end{gathered}
$$

The assumption is made that any dissolution taking place is fully supported cathodically by oxygen reduction (equation 2). Anodic and cathodic sites are determined at the solid/liquid interface according to the phases in contact with the liquid. At the beginning of each iteration, the exposed areas of each phase are assessed in order to determine any galvanic effects present, in addition to determining whether the interfacial areas are acting in an anodic or cathodic manner.

\subsection{Electrode potential}

An electrode potential is calculated for all liquid sites adjacent to solid phases using the Nernst equation. 


$$
E=E_{0}+\frac{R T}{n F} \ln \left(\frac{[\mathrm{Ox}]}{[\mathrm{Red}]}\right)
$$

where $E_{0}$ is the standard electrode potential $(\mathrm{V}), R$ is the universal gas constant $\left(\mathrm{Jmol}^{-1} \mathrm{~K}^{-1}\right), F$ is Faraday's Constant $\left(\mathrm{Cmol}^{-1}\right), T$ is the temperature $(\mathrm{K})$ and $[\mathrm{Ox}]$ and [Red] are the concentrations $\left(\mathrm{mol} . \mathrm{dm}^{-3}\right)$ of the oxidized and reduced species respectively. If the site resides next to an anodic site (zinc rich phase) then the standard electrode potential for that metal would be used and the oxidized species would be the concentration of metal cations present. Conversely, if the site is adjacent to a material predicted to behave cathodically, then the standard electrode potential for oxygen reduction in neutral conditions is used and the relative amounts of $\mathrm{OH}^{-}$and $\mathrm{O}_{2}$ is taken into account. Should a liquid site be bounded by both anodic and cathodic material then the electrode potential is taken as the weighted geometric mean of all the faces in contact with conductive solid.

\subsection{Interface potential and corrosion rate}

The electrical potential is calculated throughout the metallic solid present using a cell-centred control-volume finite difference approach to solve the Laplace equation to describe the steady-state voltage fields.

$$
\nabla(-\kappa \nabla \phi)=0
$$

Where $\kappa$ is the electrical conductivity $\left(\Omega^{-1} \mathrm{~m}^{-1}\right)$. The electrode potential is used as a fixed boundary condition at the exposed faces of the simulated solid and insulation conditions are applied to all other sides. A harmonic mean is used at the solid-liquid interface to determine the conductivity at these sites,

$$
\kappa=\frac{2 . \kappa_{S} \kappa_{L}}{\kappa_{S}+\kappa_{L}}
$$

Next, the voltages of the liquid sites at the solid-liquid interface are determined using the voltages in neighbouring solid sites, weighting each value according to interfacial area. These voltages are then used as Dirichlet boundary conditions in determining the steady-state electrical potential field throughout the electrolyte using the Laplace equation (4), assuming uniform conductivity. Again, insulation conditions are applied at all other sides of the mesh.

Having determined those phases that will act anodically and the potentials experienced at the interface, a decision is made as to what amount of material may be removed from each anodic site. This is calculated from experimentally derived data using the rotating disc electrode technique, which relates potential to current density. The local potential in the Neumann neighbourhood of an anodic site is calculated, giving a current density that is used to estimate the dissolution from the site using the area of contact. The cumulative total of electrons to be transferred during dissolution, $M_{A}$, is given by, 


$$
M_{A}=\sum_{i=1}^{l} \frac{n\left(\delta f_{i} \Delta x_{i} \Delta y_{i} \Delta z_{i}\right) \rho_{i}}{M_{r}}
$$

where $l$ is the number of sites corroding, $f_{i}$ is the volume fraction of the cell that is permitted to transform at that potential, $n$ is the number of electrons to be transferred in the oxidation of a phase, $\rho_{i}$ is the density $\left(\mathrm{kg} . \mathrm{m}^{-3}\right)$ and $M_{r}$ is the molecular mass $\left(\mathrm{kg} \cdot \mathrm{mol}^{-1}\right)$ of the phase.

\subsection{Cathodic capacity}

Assuming that the anodic dissolution taking place is fully supported cathodically by the reduction of oxygen, equation 2 , it is necessary to calculate the amount of oxygen that is available to the cathodic sites. This is the amount of oxygen that is within the diffusion length from the solid liquid interface. In our case the oxygen that is considered to be available for the cathodic processes occupies a position in the $y$ direction from the surface that satisfies equation 7 .

$$
y_{j}-y_{\text {surf }} \leq \sqrt{4 D \Delta t}
$$

where $D$ is the diffusivity of $\mathrm{O}_{2}\left(\mathrm{~m}^{2} \mathrm{~s}^{-1}\right)$ and $\Delta t$ is the time increment (s). The maximum amount of dissolution that can be supported can thus be calculated, which may result in a scaling down of the anodic processes taking place. Once the amount of material removed is determined, the volume fraction of the cells is updated, along with concentration increases made to these cells in terms of cation and $\mathrm{OH}^{-}$at anodic and cathodic sites respectively. Decreases in dissolved oxygen levels at the cathode surface are considered later in the algorithm.

\subsection{Corrosion product deposition}

Corrosion products are deposited at the surface of the simulated solid within arbitrary voltage tolerances and to an equivalent of $5 \%$ of the volume corroded within a time increment.

$$
\begin{gathered}
\mathrm{Zn}_{(\mathrm{aq})}^{2+}+\mathrm{H}_{2} \mathrm{O}_{(\mathrm{l})} \rightarrow \mathrm{Zn}(\mathrm{OH})_{(\mathrm{aq})}^{+}+\mathrm{H}_{(\mathrm{aq})}^{+} \\
\mathrm{Zn}(\mathrm{OH})_{(\mathrm{aq})}^{+}+\mathrm{H}_{2} \mathrm{O}_{(\mathrm{l})} \rightarrow \mathrm{Zn}(\mathrm{OH})_{2(\mathrm{~s})}+\mathrm{H}_{(\mathrm{aq})}^{+}
\end{gathered}
$$

This is done to follow the processes outlined in equations 8 and 9, whereby the metal cations, predominantly $\mathrm{Zn}^{2+}$, emanating from dissolution events taking place on the coating layers rapidly undergo hydrolysis reactions to produce a hydroxide film in solution. This is characterized in the model by a decrease in $\left[\mathrm{M}^{\mathrm{n}+}\right]$, an increase in $\left[\mathrm{H}^{+}\right]$and the assignment of a value for volume fraction of a liquid cell occupied by corrosion product $(p)$. This is distributed evenly amongst those cells that satisfy the tolerances arbitrarily set out in the model. 


\subsection{Mass transport}

The evolution of all of the concentration fields in the $5 \% \mathrm{NaCl}$ solution is carried out in the model using equation 10, describing the ordinary diffusion (left-hand term) and migration effects (right-hand term) experienced by a charged particle in an electrical field.

$$
\frac{\partial c_{i}}{\partial t}=-\nabla\left(D_{i} \nabla c_{i}\right)+z_{i} F \nabla\left(u_{i} c_{i} \nabla \phi\right)
$$

$D_{i}$ is the diffusion coefficient $\left(\mathrm{m}^{2} \mathrm{~s}^{-1}\right)$ for species $i, z_{i}$ is the unit charge and $u_{i}$ is the ionic mobility $\left(\mathrm{m}^{2} /(\mathrm{Vs})\right)$ calculated using the Nernst-Einstein equation:

$$
u_{i}=D_{i} \frac{z_{i} F}{R T}
$$

The diffusion coefficient of each species is altered at electrolyte sites containing corrosion products by,

$$
D_{i}^{*}=D_{i}(1-p)^{2}
$$

Clearly, if $p$ reaches unity then this cell becomes a complete barrier to diffusion. Convection is assumed to be negligible throughout the electrolyte and movement of dissolved oxygen is considered only with respect to Fickian diffusion effects.

The concentration fields are calculated iteratively using a cell-centred finitedifference method [8]. During this procedure the dissolved oxygen content of the cells adjacent to cathodic sites is continually reduced until the amount necessary to facilitate the preceding anodic dissolution is reached. After this is achieved, ordinary diffusion proceeds without the removal of any $\mathrm{O}_{2}$ concentration. During the diffusion calculation insulation boundary conditions are applied at the solidliquid interface and sides of the mesh, the top of the mesh is fixed at the initial concentration.

In order to maintain the equilibrium of the ionization of water, a procedure is undertaken post-diffusion and/or migration. This is to ensure that the corresponding $\left[\mathrm{H}^{+}\right]$and $\left[\mathrm{OH}^{-}\right]$fields are such that the ionic product remains $10^{-14}$, This procedure is carried out as to return the concentration fields to equilibrium, although still allowing fluctuations in local $\mathrm{pH}$.

\section{Results and discussion}

The results presented here are representative of those obtained from the model when simulating the destruction of synthetic microstructures in $5 \% \mathrm{NaCl}$ solutions. Concentration fields for evolving species characteristic of the anodic and cathodic processes are depicted. The normalized form of current density fields shown, taken from the steady-state voltage fields, agree with numerical solutions [9]. 
(a)

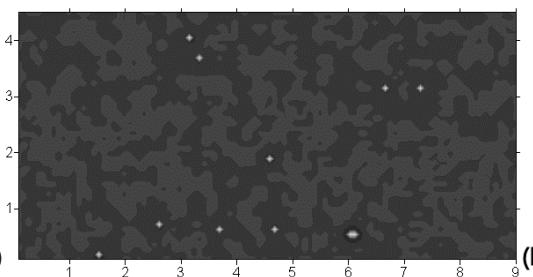

(c)

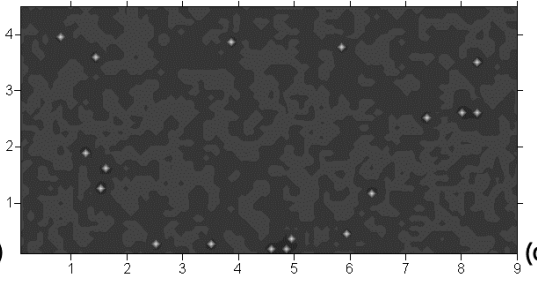

(b)

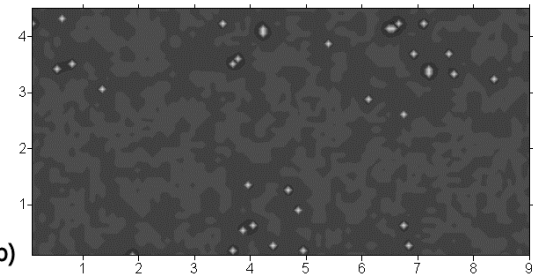

(d)

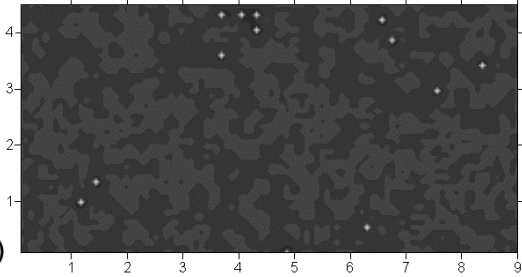

Figure 1: $\quad$ Vertical current density maps $100 \mu \mathrm{m}$ above an EZ coating after (a)12, (b)14, (c)17, and (d)19 hours, showing anodic (light) and cathodic (dark) areas. (Dimensions in $\mathrm{mm}$ ).

\subsection{Simulation of corrosion on pure zinc}

In contrast to hot-dipping, electroplating a steel substrate (EZ) yields a virtually pure layer of zinc, effectively absent of spatial variations in microstructure. Figure 1 shows the movement of anodic current densities across the surface of EZ-coated steel, which is proportional to the corrosion taking place at the surface of the simulated solid. Since the time between sequential maps is relatively small, this indicates that the location of anodic dissolution in this case is determined by the instantaneous local fluctuations in cation concentration. In addition to this the location of the cathodic activity is influenced by the differential aeration experienced across the coating.

\subsection{Influence of Hot-Dip Zn - 4.5wt.\% Microstructure}

The microstructure of a Galfan coating consists of primary zinc dendritic regions within $\mathrm{ZnAl}$ eutectic. In constructing this microstructure in the model the anodic and cathodic sites can be seen to occur at preferential sites across the solid-liquid interface, shown in figure 2. The anodic actions operating across the coating layer remain in the same position throughout the simulation whereas the cathodic potentials appear to be the subject of some flux, highlighting the availability of oxygen plays a major role in the predictions made by the model. The assumption can be made that within the model the anodes (primary zinc phase) will continue to be the subject of anodic attack until either these dendrites have been removed or the ingress of electrolyte is prevented by corrosion product formation.

The simulation of the cut-edge corrosion of a Galfan-coated-steel - steel substrate with $25 \mu \mathrm{m}$ coating on either side - can be seen in figure 3 . In this case the steel substrate can be seen to become the site dominant for cathodic oxygen reduction, thus a depletion of the oxygen field can be seen over this area in figure 
3 (right). The primary zinc phase can still be seen to be the area of the most intense anodic activity (shown by local cation releases shown in left-hand side of figure 3). In cut-edge corrosion simulations, the eutectic phase is also subject to some dissolution due to calculated galvanic effects in the model, albeit to a lesser degree.

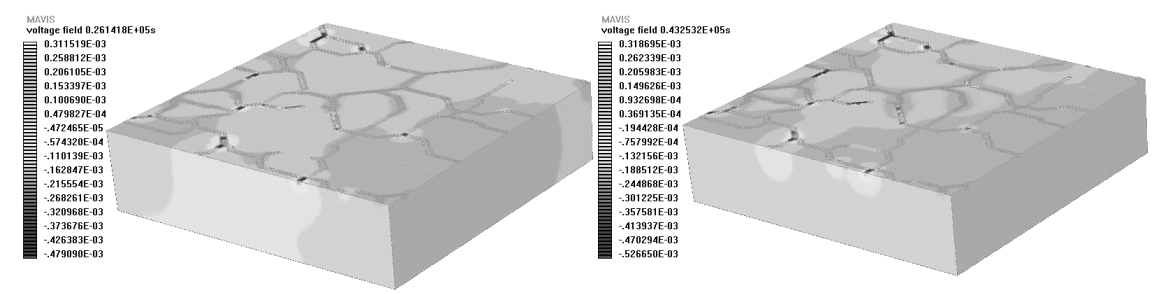

Figure 2: Electrical potential throughout the $5 \% \mathrm{NaCl}$ solution in contact with $\mathrm{Zn}-4.5 \mathrm{wt} . \% \mathrm{Al}$ coating after 7 (left) and 12 (right) hours.

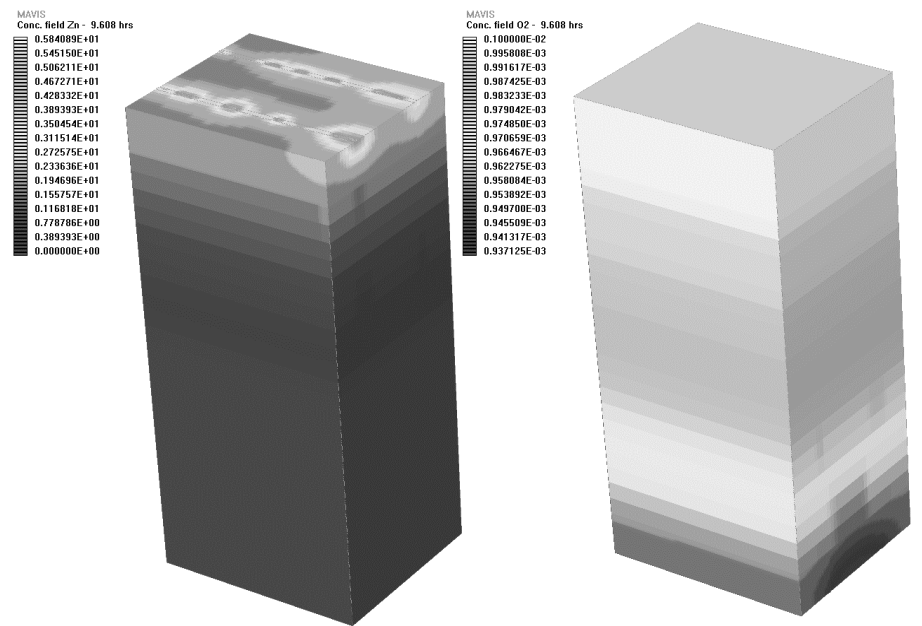

Figure 3: Evolved cation (left, inverted) and dissolved oxygen (right) concentration fields $\left(\mathrm{mol} . \mathrm{dm}^{-3}\right)$ after 9.6 hours above a Galfancoated steel cut-edge. ( $1 \mathrm{~mm}$ cut-edge length).

\subsection{Effect of magnesium addition}

For an $\mathrm{Al}$ composition of $4.5 \mathrm{wt} . \%$, small $\mathrm{Mg}$ additions increase the volume fraction of primary zinc phase. (A $0.04 \% \mathrm{Mg}$ addition yields a primary volume fraction equivalent to $18 \%$, compared to $6 \%$ without $\mathrm{Mg}$ ). Figure 4 shows the current density fields $100 \mu \mathrm{m}$ above the coating surface in aqueous $\mathrm{NaCl}$, which suggests that the coating layer with the higher primary $\mathrm{Zn}$ fraction experiences a higher frequency of anodic attack at a higher intensity. This is not unexpected since the greater area of primary zinc exposed would give a higher corrosion rate. 
(a)

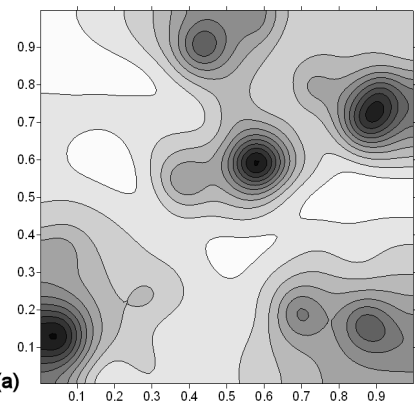

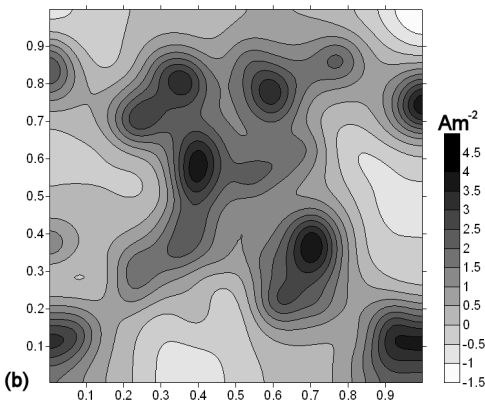

Figure 4: Current density (vertical component, $i_{y}$ ) maps for surfaces of Galfan coatings exposed to $5 \% \mathrm{NaCl}$; containing (a) $6 \%$ and (b) $18 \%$ primary phase after 7 hours simulated exposure. (Dimensions in $\mathrm{mm}$ ).

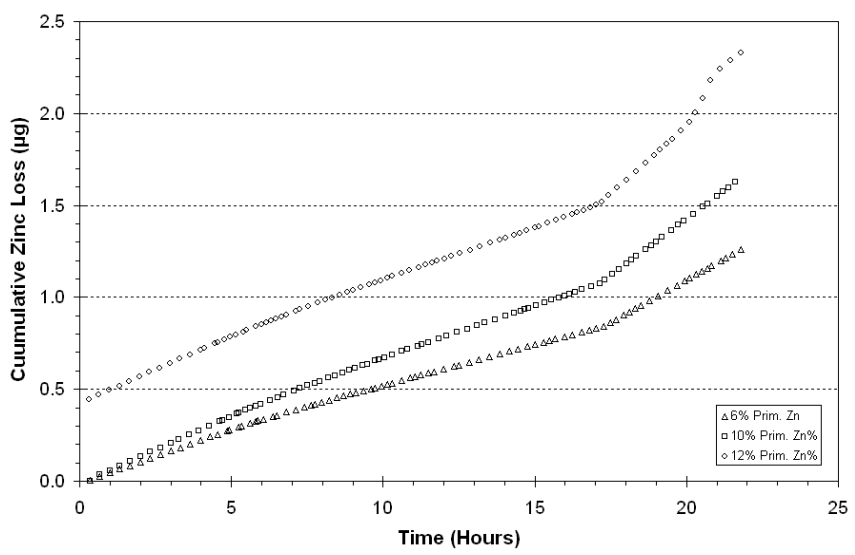

Figure 5: $\quad \mathrm{Zn}$ losses from the $\mathrm{Zn}-4.5 \mathrm{wt} . \% \mathrm{Al}$ coatings with varying volume fractions of primary Zinc phase. $\left(1 \mathrm{~mm}^{2}\right.$ area exposed).

Figure 5 shows varying zinc losses from Galfan coatings of different volume fractions of primary phase with different $\mathrm{Mg}$ additions. As expected, a proportionally higher corrosion rate is experienced from the coatings containing higher volume fractions of primary $\mathrm{Zn}$.

\section{Conclusions}

The localized corrosion effects experienced by pure zinc and Galfan-coated steel have been simulated. 3D conserved concentration fields are used to predict the electrical conditions in $5 \% \mathrm{NaCl}$ solution, which are related to experimentally derived data to predict material losses from Galfan coating layers in this aqueous environment. The form of the current density fields, along with predicted zinc losses from coating layers compares favourably with short-term experimental testing. 


\section{Acknowledgements}

The authors would like to thank H.N. McMurray, D.A. Worsley and J.A. Spittle at Swansea University (UK) for many useful discussions.

\section{References}

[1] Elvins, J., Spittle, J.A., \& Worsley D.A., "Microstructural changes in zinc aluminium alloy galvanising as a function of processing parameters and their influence on corrosion." Corrosion Science, 2005. 47: pp. 2740 2759.

[2] Seré, P.R., Culcasi, J.D., Elsner, C.I., \& Di Sarli, A.R., "Relationship between texture and corrosion resistance in hot-dip galvanized steel sheets." Surface \& Coatings Technology, 1999. 122: pp. 143-149.

[3] Panossian, Z., Mariaca, L., Morcillo, M., Flores, S., Rocha, J., Peña, J.J., Herrera, F., Corvo, F., Sanchez, M., Rincon, O.T., Pridybailo, G., \& Simancas, J., "Steel cathodic protection afforded by zinc, aluminium and zinc/aluminium alloy coatings in the atmosphere." Surface \& Coatings Technology, 2004. 190(2-3): pp. 244-248.

[4] Böhm, S., McMurray, H.N., Powell, S.M., \& Worsley, D.A., "Photoelectrochemical investigation of corrosion using scanning electrochemical techniques." Electrochimica Acta, 2000. 45: pp. 24652174.

[5] McMurray, H.N., Parry, G., \& Jeffs, B.D., "Corrosion resistance of Zn-Al alloy coated steels investigated using electrochemical impedance spectroscopy." Iron and Steelmaking, 1998. 25(3): pp. 210-215.

[6] Brown, S.G.R., Barnard, N.C., \& McMurray, H.N., "3-dimensional modelling of localized corrosion effects in zinc and zinc alloy steel coatings." CIMTEC 2004. Acireale(CT), Italy: Techna Group.

[7] Brown, S.G.R., \& Barnard, N.C., "3D computer simulation of the influence of microstructure on the cut edge corrosion behaviour of a zinc aluminium alloy galvanized steel." Corrosion Science, 2006. 48(8): pp. 2291-2303.

[8] Patankar, S.V., Numerical Heat Transfer and Fluid Flow. Computational methods in mechanics and thermal sciences. 1980: Hemisphere. 214.

[9] Livingstone-Bridge, D., Myland, J.C., \& Oldham, K.B., "A model of ionic current densities in the vicinity of a corroding disk-shaped region." Electrochemistry Communications, 2001. 3: pp. 384-389. 